\title{
The Impact of Trusted and Secured Transactions in an E-Commerce Environment on Consumers' Behaviour: The Case of Saudis in the UK
}

\author{
Haya Alshehri, Farid Meziane \\ University of Salford, UK
}

\begin{abstract}
The work reported in this paper is part of a larger study that attempts to compare the online activities of Saudis living in Saudi Arabia and those living in the United Kingdom (UK). The study aims to answer the question on whether the environment plays a key role and impact on the activities of Saudis online customers. This paper deals only with the research conducted in the UK and attempts to understand the activities and perception of Business to Customer (B2C) E-Commerce (EC) among Saudis living in the UK. This study tries to assess the impact of the environmental change on the online shopping behaviour. Quantitative data was collected from 169 Saudis living in the UK. Trust in both security and payment (SP) were tested as well as nine hypotheses. The results confirm that there is a high number of Saudi residents living in the UK trusting the security and payment systems when engaging in online transactions in the UK. Furthermore, the outcomes of hypotheses testing show that the new secured and trusted environment affects Saudis consumers in the UK. Hence, these primary results suggest that the environment plays an important role in changing the shopping behaviors of online customers.
\end{abstract}

\section{Introduction}

Over the last two decades, E-Commerce is one of the most discussed themes in business, and much research has been conducted on various issues related to it. E-Commerce allows companies to access new customers and markets, as items and services can be offered to more geographically-dispersed buyers [14]. Zhu [23] identified many risks as E-Commerce increases and develops, and emphasised on the impacts of this phenomenon on economies, politics and the law. E-Commerce is developed in the Western world but struggles to achieve the same success in developing countries. The UK is one of the most developed countries in Western Europe in its use of B2C E-Commerce, and thus forms a useful case for examining how success is achieved in this respect. Researchers have explored E-Commerce in the UK from different viewpoints. For example, Matlay \& Addis [7] investigated the views of small companies' managers and owners in the UK and found that they are aware of the potential advantages to be gained from using Information and Communication Technologies (ICT) and ECommerce. According to the Centre for Retail Research (CRR) [2], the UK online share of retailing was expected to rise from $12.1 \%$ in 2013 to $13.5 \%$ in 2014 but actually reached $15.8 \%$. Kamalabadi et al. [16] have observed that many companies in developing countries are in the initial phases of implementing E-Commerce.

The poor security of the online environment with respect to personal information being illegally accessed is a major challenge to E-Commerce [10] and the optimal use of security measures is essential to create the trustworthiness needed to assist the growth of B2C E-Commerce [3]. Hence, steps must be taken by online retailers to prevent security breaches and fraud, and this means that all potential security problems should be recognised, identified, controlled, and effectively managed/prevented [9]. The purpose of this study is to investigate the environmental influence affecting Saudi citizens in using B2C E-Commerce with regards to their perspective on security and payment in an advanced E-Commerce environment such as the UK. We will endeavour to answer the question based on the outcomes of previous studies.

The data collected from a questionnaire survey of 169 Saudi citizens living in the UK is the basis of the results reported in this paper. The key factors that were tested are the influences of security and the online payment systems. The following questions were asked to investigate security and online payment systems for B2C E-Commerce websites. Each question is labeled as Security and Payment (SP) from statement 1-9.

- I do not mind providing my payment details to the UK companies (SP-statement 1);

- I do not mind providing my payment details to overseas companies (SP-statement 2);

- I prefer companies that provide different payment methods (SP-statement 3);

- Companies must have a secure payment system (SP- statement 4);

- Companies should make the security of the payments clear on their websites (SP- statement 5); 
- The technology used to protect online payments is very important (SP-statement 6);

- I do not mind for my payment details to be stored by the company for future transactions (SPstatement 7);

- It is important that companies' websites have a guidance explaining the payment method (SPstatement 8);

- I will buy online if my bank guarantees my transaction to be safe (SP- statement 9).

There are also nine main hypotheses in total $\left(\mathrm{H}_{1}\right.$, $\mathrm{H}_{2}, \mathrm{H}_{3}, \mathrm{H}_{4}, \mathrm{H}_{5}, \mathrm{H}_{6}, \mathrm{H}_{7}, \mathrm{H} 8$ and $\mathrm{H}_{9}$ ) that were tested and subjected to the Chi-Square Test. These will be discussed in detail in the findings section. The remaining of the paper is structured as follows. In section 2 we provide a background review for this study in the form of a literature review and in section 3 the research methodology is described. The findings and analysis of this research are presented in section 4 and discussed in section 5. Finally, the paper concludes in section 6 .

\section{Literature Review}

\subsection{Background}

In this age of technological growth, E-Commerce is one of the important developments around the world in the business and commerce areas. With such growth, E-Commerce is essentially changing countries' economies and the commercial methods by which they are managed [16]. Since online companies that are effective in their conduct of business, promote satisfaction and loyalty amongst their customers, who return to them in the sound knowledge that their purchasing will be trouble-free [14]. Mostafaeipour [1] stated that the benefit associated with E-Commerce is the savings which are possible for parties to a purchase/sale transaction to realise, since transportation, paperwork, and timewasting are all reduced. In fact, the situation is similar in many developing countries where ICT infrastructures are still in their infancy and therefore do not support the development of E-Commerce [21]. AlGhamdi et al. [18] noted that with respect to ECommerce, the growth in Saudi Arabia has not met its initial predictions and is not what is expected from a nation with such importance in the global economy. In addition, Companies in Saudi Arabia do not appear to be following the developed countries' rapid growth in E-Commerce [18]. Therefore, Alshehri and Meziane [5] reported that there is an absence of studies that show a good understanding of how Saudi customers behave with regards to shopping online when they live in a developed country and then attempt to recreate similar environment back home to assist the growth of E-Commerce.

\subsection{Trust}

Trust is an important factor and plays a key role in E-Commerce activities because customers and vendors do not see each other. It is vital to ensure the success of E-Commerce that is fundamentally different from traditional business [21]. One of the major obstacles for the adoption and development of E-Commerce is the lack of trust [21], and the trust deriving from this kind of personal interaction plays a significant role in various social and economic backgrounds where doubt and dependency may perhaps be key ingredients [1]. Trust is even more important for the younger generations as they form the largest part of the internet users and spend more on E-Commerce [8]. Over 50\% of the Saudis population use the Internet between one to ten hours per day and about $70 \%$ use the Internet more than once a day [6]. The recognized important issues in B2C in Saudi Arabia are "the user interface quality, service information quality, security risk perception, and privacy perception" [12]. AlGhamdi et al. [18] reported that the anxiety about 'stolen credit cards numbers' is sometimes stated together with the inability 'in providing a secure payment platform' as the main reasons for Saudis to not engage in ECommerce. Two of their interviewed participants stated that "buying from outside Saudi Arabia is safer than buying from an e-retailer inside Saudi Arabia" and "people have perceptions that Arabic e-retailers are not trustworthy".

\subsection{Security and Payment Systems}

Many studies have shown that payment systems are the main obstacles to the development of ECommerce. Malhotra et al. [17] found that information privacy features as one of the main obstacles to the development of E-Commerce and this was confirmed by the study conducted by Belanger et al [3]. The worry about personal information being stolen as a result of insecure systems in E-Commerce companies is significant [11] and online payment systems have been acknowledged as a key trust concern [20]. It is recommended that payment methods, information together with an explanation should be include on the website for all the steps that customers follow to make a payment $[19,13]$. In this respect, Zhu [23] suggests the implementation of various strategies to increase security awareness among businesses, including educational and training initiatives in 
respect to E-Commerce, and efforts to support the development of techniques for E-Commerce security and to build environments for the promotion of effective E-Commerce [23]. Customers all around the world want to safeguard their personal financial information and do have concerns about their information being captured by hackers [15]. The present infrastructure in Saudi Arabia is not sufficiently trustworthy to instill complete confidence in Saudi customers to disclose their financial details over the Internet [4], and consequently, the method of payment is a foremost problem which must be solved [1]. It was outlined that security and online payment are one of the key factors that impact on Saudi online customers to buy or not to buy when they live overseas [5]. In the Saudi context, several issues are currently causing the slow development of E-Commerce, and the lack of effective payment systems, and the difficulties encountered in transacting with banks are among these [22]. As instant first step forward, the companies involved in B2C E-Commerce have a duty to publish more information about the security of their payment systems information online.

\section{Research Methodology}

As outlined in the above sections, the results reported in this study are based on the outcomes from earlier research. Quantitative data was applied in this part of the study. A pilot investigation was used to evaluate the questionnaires to develop data validity and reliability. It was distributed in different cities of the UK and include Manchester, Liverpool, London, Norwich, Cardiff and Bangor. The questionnaire was developed following a logical order, starting, with respondents' demographic data, then followed by sections looking at their usage of the Internet. The next unit is to investigate their experiences in using E-Commerce. The last section contains the independent factors and consist of "ICT infrastructure, Culture, Payment, Security, Privacy, Integrity, Personal Information and Fulfillment of Transactions". The participants were requested to provide their belief on whether they agreed or disagreed with each item using the Likert scale of 15 where 1 was "strongly disagree" and 5 was "strongly agree. In addition, Statistical Package for the Social Sciences (SPSS) software was used to analyze this part of the study. Frequency and percentages were also used and presented in the form of Figures and Tables. The Chi-Square Test was conducted to test the hypothesis of this study.

\section{Finding}

\subsection{Demographic and additional Information}

Figure 1 summarises the demographic information of Saudi citizens living in the UK of the respondents' sample and these were as follows: 80 were males $(47.3 \%)$ and 89 females $(52.7 \%)$; the age group 25-34 was the largest, containing 79 respondents $(46.7 \%)$, and the age group over 55 was the smallest with just one respondent $(6 \%)$. With respect of the education levels, the largest group comprised respondents with a bachelor's degree and their number was 65 representing $38.5 \%$ of the sample.

In terms of location, Figure 2. illustrates that the respondents were spread throughout the UK. The middle region attracted the highest number of respondents with $67.5 \%$, followed by the west with $27.8 \%$. With respect to income, $31.4 \%$ of the respondents earned between 4,000RS (Saudi Riyal) and 8,000RS, and 5.3\% earned over 20,000RS. In terms of occupation, $39.1 \%$ of the sample were students, $37.9 \%$ were in employment, and $17.8 \%$ were the spouses of Saudis [5].
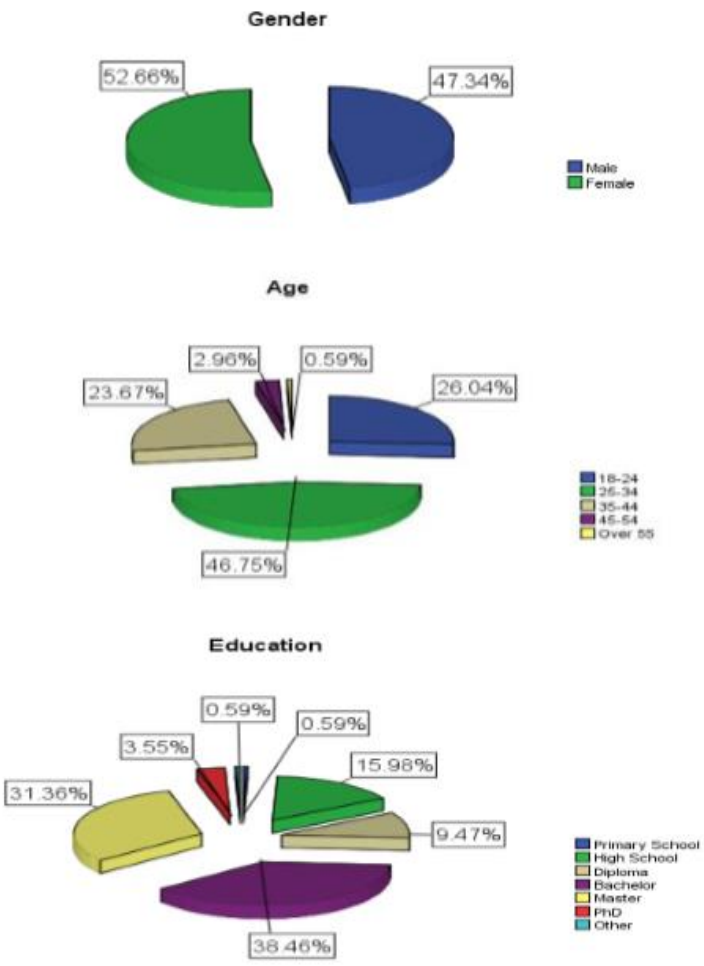

Figure 1. Demographic Information 


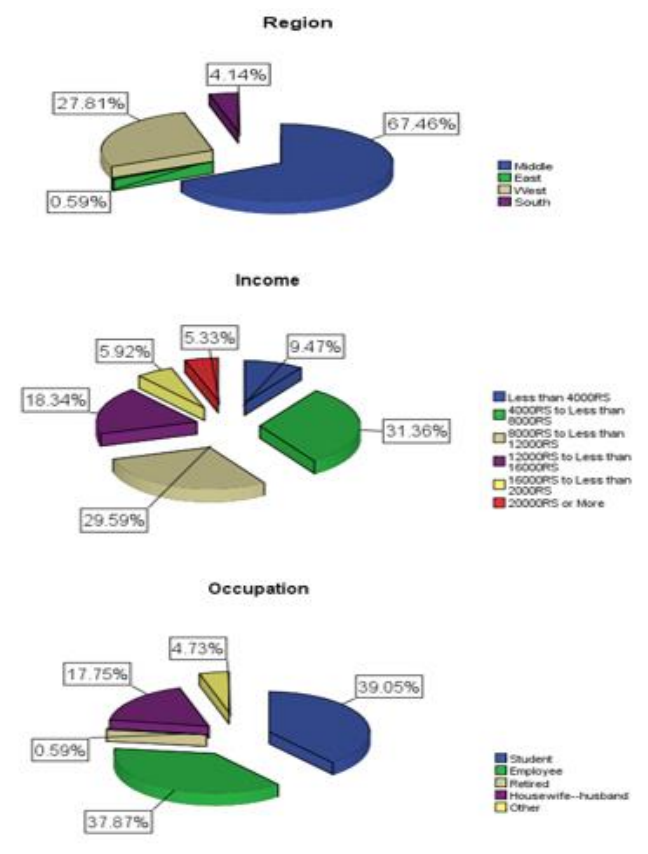

Figure 2. Demographic Information

In addition, Table 1 . Shows in respect to their websites usage it was shown that $29 \%$ buy only from UK retailers, and $20.1 \%$ buy only from overseas retailers. Furthermore, $22.5 \%$ buy from both UK and overseas online retailers.

Table 1. Websites usage

\begin{tabular}{|c|c|c|c|}
\hline *Item & & $\mathrm{N}$ & $\%$ \\
\hline \multirow{9}{*}{ 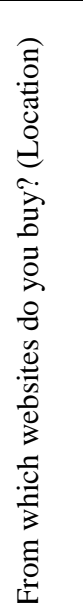 } & Overseas retailers & 34 & 20.1 \\
\hline & UK retailers & 49 & 29.0 \\
\hline & Other & 2 & 1.2 \\
\hline & I do not know & 3 & 1.8 \\
\hline & $\begin{array}{l}\text { Saudi, and overseas } \\
\text { retailers }\end{array}$ & 4 & 2.4 \\
\hline & $\begin{array}{l}\text { Saudi, overseas and UK } \\
\text { retailers }\end{array}$ & 9 & 5.3 \\
\hline & Saudi and UK retailers & 6 & 3.6 \\
\hline & Overseas and UK retailers & 38 & 22.5 \\
\hline & All that apply & 2 & 1.2 \\
\hline
\end{tabular}

Table 2 presents the findings regarding E-Commerce readiness, revealing that just under half $(48.5 \%)$ of the sample believed they were ready to use the Internet as their main shopping medium, while just over half $(51.5 \%)$ felt they were not.
Table 2. E-Commerce Readiness

\begin{tabular}{|c|c|c|c|c|c|c|}
\hline Question & \multicolumn{2}{|c|}{ Yes } & \multicolumn{2}{|c|}{ No } & \multicolumn{2}{|c|}{ Total } \\
\hline Are you & $\#$ & $\%$ & $\#$ & $\%$ & $\#$ & $\%$ \\
\hline $\begin{array}{l}\text { the Internet } \\
\text { as your main } \\
\text { shopping } \\
\text { medium? } \\
\text { UK? }\end{array}$ & 82 & $\begin{array}{l}48 . \\
5\end{array}$ & 87 & $\begin{array}{l}51 \\
.5\end{array}$ & 169 & $\begin{array}{l}100 \\
.0\end{array}$ \\
\hline
\end{tabular}

Table 3 shows the online shopping habits of Saudis living in the UK, from which it can be seen that from the sample, $60.4 \%$ only use websites where the language is English, $6 \%$ only use websites in Arabic, whereas 25.4 use both languages.

Table 3. Languages usage

\begin{tabular}{|l|l|l|l|}
\hline Items & Description & Frequency & Percent \\
& & & \\
\hline From which & Arabic & 1 & \\
websites do & English & 102 & 60.4 \\
you buy? & Both & 43 & 25.4 \\
(Language) & Other & 1 & .7 \\
\hline
\end{tabular}

\subsection{Analysis of Security and Payment}

The following Figures show the analysis of all statements stated in the introduction section. The results are reported in percentages.

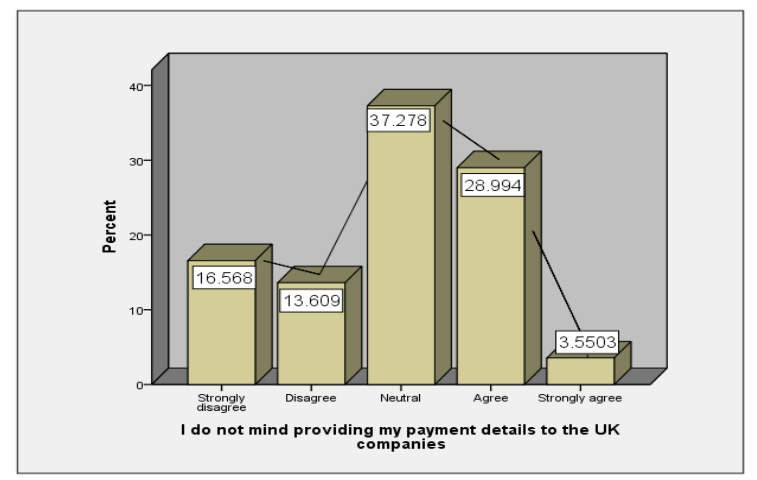

Figure 3. SP- statement 1

Figure 1 concerns whether people do mind in providing their payment details to the UK companies. The results obtained are as follows: $3.5 \%$ agree strongly, $16.5 \%$ disagree strongly, $28.9 \%$ agree, $13.6 \%$ disagree. Hence, there was a fairly balanced response with $32.4 \%$ of respondents in agreement 
and $30.1 \%$ not. A very large percentage (37.2\%) did not give their opinion and recorded a neutral answer.

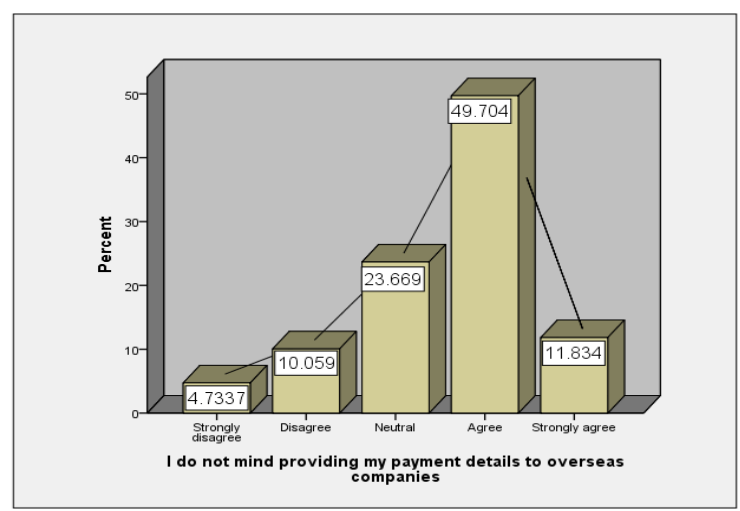

Figure 4. SP- statement 2

Figure 2 concerns whether people mind providing their payment details to overseas companies. The results obtained are as follows: $11.8 \%$ agree strongly, $4.7 \%$ disagree strongly, $49.7 \%$ agree, and $10 \%$ disagree. Hence, $61.5 \%$ agree that they do not object to providing their payment details to overseas companies while $14.7 \%$ disagree with the statement. However, almost one quarter $(23.6 \%)$ were not sure what they felt and recorded a neutral answer.

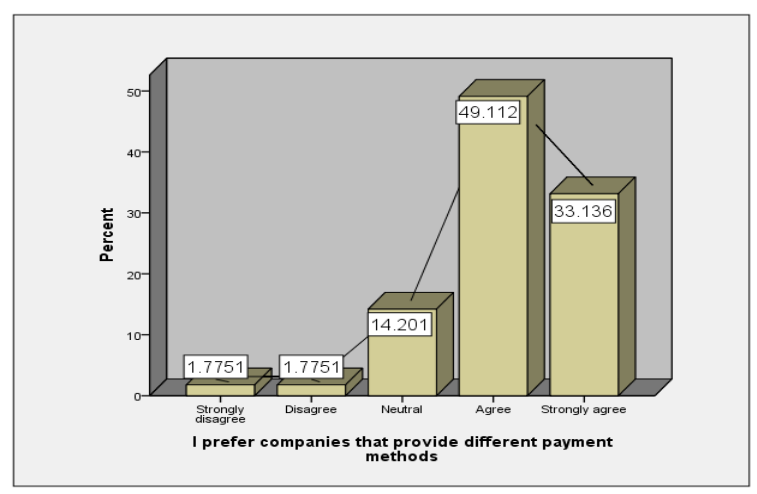

Figure 5. SP- statement 3

Figure 3 refers to the statement that people prefer companies that provide different payment methods, and from this we can see that $33.1 \%$ agree strongly, $1.7 \%$ disagree, $49.1 \%$ agree, and $1.7 \%$ disagree. Overwhelmingly, a majority of $82.2 \%$ agree with this statement and only $3.4 \%$ disagree, so it is clear that most people prefer the opportunity to choose from different payment methods. However, 14.2\% provided a neutral response.

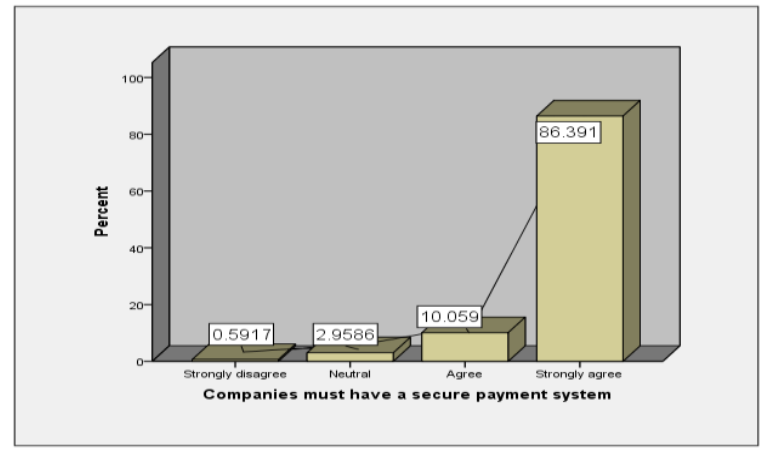

Figure 6. SP- statement 4

Figure 4 relates to the statement that people believe companies must have a secure payment system, and in the reported answers, response $86.3 \%$ agree strongly, $0.5 \%$ disagree, strongly, and $10 \%$ agree. Hence, the vast majority of the sample (96.3\%) think it is necessary for online sellers to have a secure payment system, and only $0.5 \%$ disagree. A small percentage $(2.9 \%)$ gave a neutral answer.

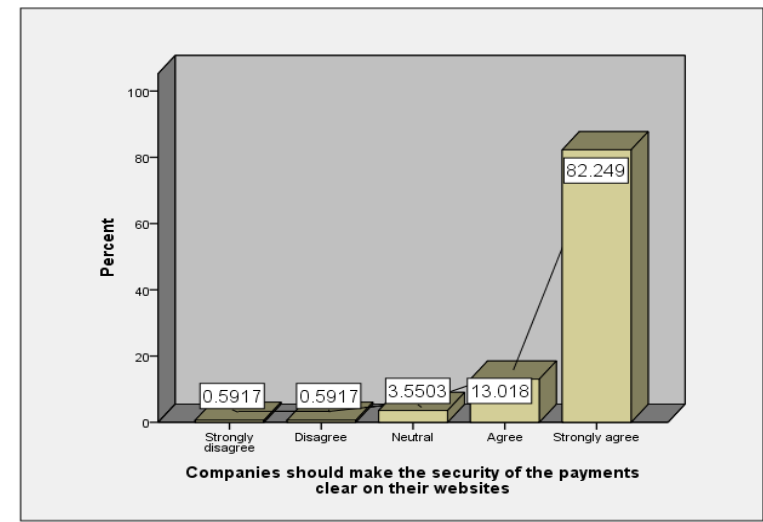

Figure 7. SP- statement 5

Figure 5 indicates whether people believe that companies should make the security of their payments clear, which means companies should make a statement on their websites to the effect that all payments are secure. In this respect $82.2 \%$ agree strongly that they should, only $0.5 \%$ disagree strongly, $13 \%$ agree, and only $0.5 \%$ disagree. Therefore, overall, $95.2 \%$ agree and $1 \%$ disagree with this idea, pointing to the need for companies to make the security of the payments clear on their websites. 


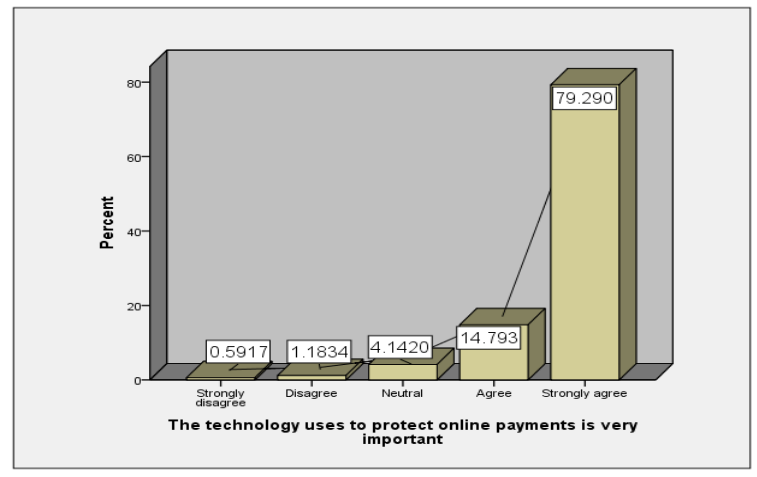

Figure 8. SP- statement 6

A small percentage of $3.5 \%$ gave a neutral answer. Figure 6 shows whether people believe that the technology used to protect online payment is very important, which means that they expect the companies to pay attention to the use of technology. Responses to this statement are as follow: $79.2 \%$ agree strongly, only $0.5 \%$ disagree strongly, $14.7 \%$ agree, and only $1.1 \%$ disagree. Therefore, in total, $93.9 \%$ agree $1.6 \%$ disagree, showing a very large majority of respondents are concerned with the protection of their online payments. A small percentage $(4.1 \%)$ of the sample did not give an opinion other than to be neutral.

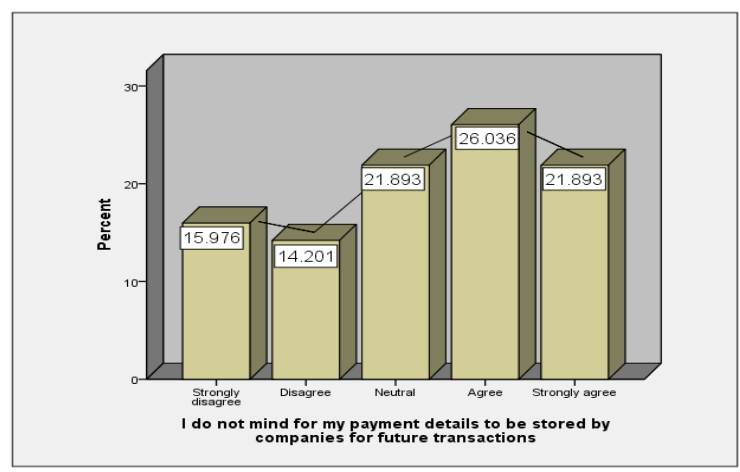

Figure 9. SP- statement 7

Figure 7 refers to whether people are happy for their payment details to be stored by the company for future transactions, and this shows that $21.8 \%$ agree strongly, $15.9 \%$ disagree strongly, $26 \%$ agree, and $14.2 \%$ disagree. Therefore, overall, $47.8 \%$ do not mind that their payment details are being stored for future transactions, whilst $30.1 \%$ do. This is clearly a majority who are happy with that situation. However, almost one quarter of the sample $(21.8 \%)$ had not made up their minds and gave a neutral answer.

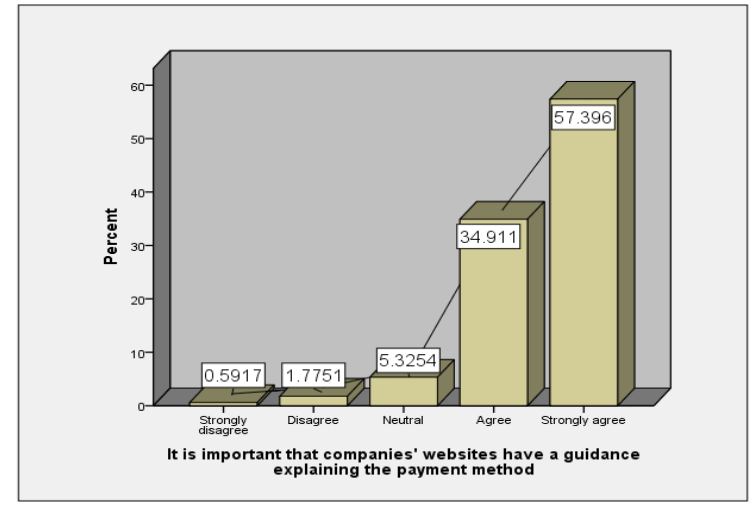

Figure 10. SP- statement 8

Figure 8 concerns the statement that people believe that it is important that companies' websites contain guidance explaining the payment method, and for this statement, $57.3 \%$ agree strongly, only $0.5 \%$ disagree strongly, $34.9 \%$ agree, and only $1.7 \%$ disagree. Therefore, as whole, a large majority of $92.2 \%$ agree and only $2.2 \%$ disagree, thus confirming the importance of companies providing comprehensive instructions regarding the payment method. A small number of respondents $(5.3 \%)$ did not offer an opinion and simply recorded a neutral answer.

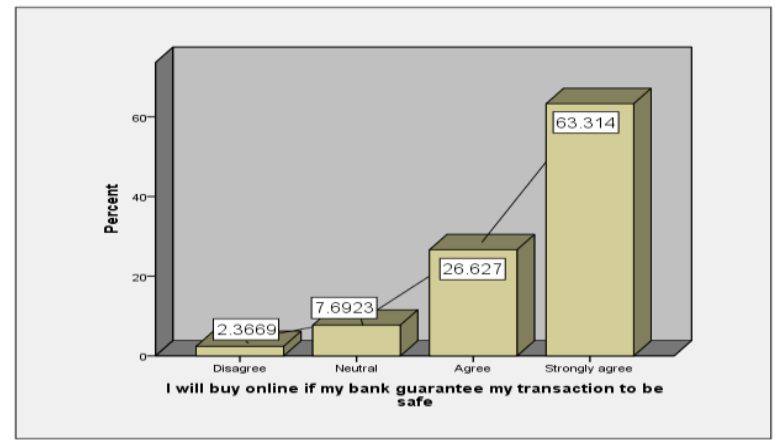

Figure 11. SP-statement 9

Figure 9 reveals whether people will buy online if their bank guarantees their transactions to be safe. In this respect, $63.3 \%$ agree strongly that they would do so in this situation, $26.6 \%$ agree, and a very small percentage $(2.3 \%)$ disagree. Consequently, a majority of $89.9 \%$ of the sample are happy to buy online if they are supported in this way by their bank, and only $2.3 \%$ are not. A small percentage (7.6\%) were not sure either way and gave a neutral answer. 
Table 4. Summary of the results

\begin{tabular}{|l|l|l|l|l|l|}
\hline *tem & SA $\%$ & A $\%$ & N \% & D \% & SD \% \\
\hline SP-1 & 3.6 & 29.0 & 37.3 & 13.6 & 16.6 \\
\hline SP-2 & 11.8 & 49.7 & 23.7 & 10.1 & 4.7 \\
\hline SP-3 & 33.1 & 49.1 & 14.2 & 1.8 & 1.8 \\
\hline SP-4 & 86.4 & 10.1 & 3.0 & - & .6 \\
\hline SP-5 & 82.2 & 13.0 & 3.6 & .6 & .6 \\
\hline SP-6 & 79.3 & 14.8 & 4.1 & 1.2 & .6 \\
\hline SP-7 & 21.9 & 26.0 & 21.9 & 14.2 & 16.0 \\
\hline SP-8 & 57.4 & 34.9 & 5.3 & 1.8 & .6 \\
\hline SP-9 & 63.3 & 26.6 & 7.7 & 2.4 & - \\
\hline
\end{tabular}

*Strongly Agree (SA), Agree (A), Neutral (N), Disagree (D) and Strongly Disagree (SD).

\subsection{Hypotheses Testing of Security and Payment}

Table 3 provides the results obtained for each hypothesis. This test for this sample is applied in order to distinguish the significance (and hence, the similarities if there are any) in different environments with the same group of people. Using this method, it is possible to establish whether there are any differences that are statistically significant. Nine main hypotheses were developed in total $\left(\mathrm{H}_{1}, \mathrm{H}_{2}, \mathrm{H}_{3}\right.$, $\mathrm{H}_{4}, \mathrm{H}_{5}, \mathrm{H}_{6}, \mathrm{H}_{7}, \mathrm{H}_{8}$ and $\mathrm{H}_{9}$ ) were subjected to the ChiSquare Test and the results are as follows:

H1. There is a high level of trust by Saudi citizens in the UK as they do not mind providing their payment details to the UK companies

H2. There is a high level of trust by Saudi citizens in the UK as they do not mind providing their payment details to overseas companies

H3. There is a significant preference by Saudi citizens living in the $U K$ in companies that provide different payment methods

H4. There is a significant believe by Saudi citizens living the UK who think, companies must have a secure payment system

H5. There a significant believe by Saudi citizens living the UK who believe, companies should make the security of the payments clear on their websites
H6. There is a high level of believe by Saudi citizens living the UK, that the technology used to protect online payments is very important

H7. There is a high level of trust by Saudi citizens in the UK as they do not mind for their payment details to be stored by the company for future transactions

H8. There is a significant believe by Saudi citizens living the UK who think, it is important that companies' websites have a guidance explaining the payment methods

H9. There is a high level of trust by Saudi citizens living the UK who think they will buy online if their bank guarantees their transaction to be safe

The Chi-Square Test was conducted to test the hypothesis of this study and also to discover the significance of security of the payment transactions and results of customers' beliefs. These are displayed in Table 5. Therefore, it is evident that the value of Asymptotic Sig is (0.000) which is less than the significance level of 0.000 for all hypotheses. Consequently, it is determined that security and payment transactions significantly affect Saudis in the UK regarding their influence of advanced and Secure E-Commerce Environment in the UK. Thus, all hypotheses were accepted.

Table 5. Chi-Square Test

\begin{tabular}{|l|l|l|l|}
\hline Items & Chi-Square & Mean & $\begin{array}{l}\text { Asymp } \\
\text { Sig. }\end{array}$ \\
\hline H1. & 59.373 & 2.8935 & .000 \\
\hline H2. & 109.373 & 3.5385 & .000 \\
\hline H3. & 145.172 & 4.1006 & .000 \\
\hline H4. & 342.976 & 4.8166 & .000 \\
\hline H5. & 418.071 & 4.7574 & .000 \\
\hline H6. & 382.331 & 4.7101 & .000 \\
\hline H7. & 7.893 & 3.2367 & .000 \\
\hline H8. & 215.053 & 4.4675 & .000 \\
\hline H9. & 154.290 & 4.5089 & .000 \\
\hline
\end{tabular}




\section{Discussion}

The literature has outlined that E-Commerce usage, security and payment, of online sellers as issues influencing the behaviour of Saudis toward engaging in E-Commerce. These results are similar to, and support the study conducted by [3, 11, 17], that found information privacy to feature as one of the main obstacles to the development of ECommerce.

Development of trust depends on the levels of trust. According on our finding $86.4 \%$ of customers strongly agreed that companies must have a secure payment system supporting the results reported in [18] when they reported anxiety about 'stolen credit cards numbers' and the lack 'in providing a secure payment platform'.

As shown above, concerns about payment over the Internet must be allayed if the integrity of the entire system is not to be challenged. Thus, stages must be implemented by online venders to avoid security breaches and fraud [9]. The poor security of the online environment in respect of personal information being illegally accessed is a major challenge to E-C-commerce [10], and the optimal use of security measures is essential to create the trustworthiness needed to assist the growth of ECommerce [3]. In the Saudi context, several issues are currently causing the slow development of ECommerce, and the lack of effective payment systems, and the difficulties encountered in transacting with banks are among these [22],. These problems generate a lack of trust which is identified as the greatest deterrent to customers' confidence in Internet payment systems, and as a result there should be access to secure online payment gateways to guarantee safety when paying for goods and services online [19] Simultaneously, during the purchase operation, companies should provide step-by-step information for customers and real-time assurances of how their information is being handled [13]. This is particularly important where Web merchants do not have real-world equivalents of their Web stores (e.g., amazon) since there is no possibility to visit in person in the event of a problem. According to [20], access to secure online payment platforms is the best way to rise the protection of online payment and this is also confirmed by this study. Therefore, Security and Payment have strong impact of encouraging Saudis in the UK.

\section{Conclusion}

This study was carried out to investigate the environmental influence affecting Saudi citizens in using E-Commerce in the UK with regards their perspective to security and payment in an Advanced E-Commerce Environment.

The outcomes are provided in the previous section. In general, a significant analysis of these early results shows that, Saudis in the UK are more open and/or have trust in providing their payment details when shopping online. It is worth noting the difference in accepting Saudi customers to provide their payment details.

All hypotheses reveal a significance in respect of customer satisfaction regarding developed ECommerce environments, as the security of the transactions in payment systems is very high. Therefore, the alternative hypotheses are that there are secure payment transaction systems regarding the satisfaction with using the online payment of Saudi citizens living in the UK, are upheld. These results suggest that secure advanced environments of online transactions really do affect online shopping. Specifically, they indicate that when customers find a developed online environment, they feel confidence in their online transactions. Therefore, their engagement with E-Commerce increases, which thereby increases the secure online environment, regardless of the customers' background.

\section{References}

[1] A. Mostafaeipour, "Contagion Aspects of Implementing E-commerce: A Case Study of B2C". International Journal of Computer Applications, Vol. 29, No. 10, pp. 32-40, 2011.

[2] Centre for Retail Research (CRR), 2014. [online], http://www.retailresearch.org/onlineretailing.phplast accessed on 11 May 2016.

[3] F. Belanger, J.S. Hiller, \& W. J. Smith, "Trustworthiness in electronic commerce: the role of privacy, security, and site attributes", The Journal of Strategic Information Systems, Vol.11, No. 3, pp. 245-270, 2002.

[4] H. A. Al-Salamin, \& A. A. Al-Hammad, "Attitude of Consumers towards Online Shopping With Special Reference to Al-Hassa Region (KSA)", Journal of WEI Business and Economics, Vol. 3, No. 3, pp. 39-56, 2014.

[5] H. Alshehri, \& F. Meziane, "An Investigation into Saudi Online Shoppers' Behaviour Abroad”, Developments in eSystems Engineering (DeSE), IEEE Xplore. Abu Dhabi, pp. 323-327, , December 2013 [Sixth International Conference. Abu Dubi. 2013]

[6] H. Alshehri, and F. Meziane, "Current State of Internet Growth and Usage in Saudi Arabia and Its Ability to Support E-Commerce Development", Journal of Advanced Management Science, Vol. 5, No. 2 pp. 127-132, March 2017. Doi. 10.18178/joams. 5.2. 127-123. 
[7] H. Matlay \& M. Addis, "Adoption of ICT and ecommerce in small businesses: an HEI-based consultancy perspective", Journal of Small Business and Enterprise Development, Vol. 10, No. 3, pp. 321-335, 2003.

[8] I. Araujo, "Establishing Long-Term trust in ecommerce", International Conference E-Commerce, pp.422, 2004.

[9] J. K. Shim, A. A. Qureshi, J. G. Siegel, \& R. M. Siegel, "The international handbook of electronic commerce", Routledge, 2013.

[10] M. Alini, "Identifying application barriers of electronic commerce regarding agricultural products in Iran using the Delphi method", WALIA journal, Vol.30, No.1, pp. 289-295, 2014.

[11] M. Head and K. Hassanein, "Trust in e-Commerce: Evaluating the Impact of Third Party Seals", Quarterly Journal of Electronic Commerce, Vol. 3, No. 3, pp. 307325. 2002.

[12] M. I. Eid, "Determints of EC customer satisfaction, trust, and loyalty in Saudi Arabia", Journal of Electronic Commerce Research, Vol. 12, N0 1, pp. 78-93, 2011.

[13] M. Jehangir, P.D.D. Dominic, Naseebullah, and A. Khan, "Towards Digital Economy: The Development of ICT and E-Commerce in Malaysia", Modern Applied Science, Vol. 5, No. 2. pp. 171-178, 2011.

[14] M. Sobihah, M. Mohamad, N. A. M. Ali, \& W. Z. W. Ismail, "E-Commerce Service Quality on Customer Satisfaction, Belief and Loyalty: A Proposal", Mediterranean Journal of Social Sciences, Vol. 6, No. 2, 260-266. 2015.

[15] M. S. Shahibi, \& S. K. W. Fakeh, "Security Factor and Trust in E-Commerce Transactions", Australian Journal of Basic and Applied Sciences, Vol. 5, No. 12, pp. 2028-2033, 2011.

[16] Kamalabadi, A. Bayat, P. Ahmadi, \& A. Ebrahimi, "Identifying and Prioritization of Challenges and Barriers of EC Implementation in Iran",World Applied Sciences Journal, Vol. 5, No.5, pp.590-597, 2008.

[17] N. K. Malhotra, S. S. Kim, \& J. Agarwal, "Internet users' information privacy concerns (IUIPC): The construct, the scale, and a causal model". Information Systems Research, Vol. 15, No.4, pp.336-355, 2004.

[18] R. AlGhamdi, S. Drew, \& O. AlFaraj, "Issues Influencing Saudi Customers' Decisions to Purchase from Online Retailers in the KSA: A Qualitative Analysis" European Journal Scientific Research, Vol.55 No.4 pp.580593, 2011(a)

[19] R. AlGhamdi, S. Drew, \& W. Al-Ghaith, "Factors influencing E-Commerce adoption by retailers in Saudi
Arabia: a qualitative analysis", The Electronic Journal on Information Systems in Developing Countries, Vol. 47, No. 7, pp.1-23, 2011(b)

[20] R. AlGhamdi, S. J. Nguyen, A. Nguyen and S. Drew, "Factors influencing e-commerce adoption by retailers in Saudi Arabia: a qualitative analysis", International Journal of Electronic Commerce Studies, Vol. 3 No. 1, pp. 83-100, 2012 (c).

[21] S. A. A. Rajon, Abdullah-Al-Nahid, and A. S. M. Arif, "A Generic Framework for Implementing Electronic Commerce in Developing Countries", ISSN, 2078-5828, Vol. 01, pp. 42-53, 2011, IJCIT,

[22] SOCG (Sacha Orloff Consulting Group). "ECommerce in Saudi Arabia: Driving the evolution, adaption and growth of e-commerce in the retail industry", 2012, [online] http://sacha-orloff-group.com, last accessed in 12 March 2017.

[23] Y. Zhu, "Research on the Data and Transaction Security of Enterprise E-Commerce Countermeasure", International Journal of Security and Its Applications, Vol. 7, No. 6, pp. 259-268, 2013. 